MATEC Web of Conferences 13,03009 (2014)

DOI: 10.1051/matecconf/ 20141303009

(C) Owned by the authors, published by EDP Sciences, 2014

\title{
Computational Analyses of Passive Wet Gas Separation in Branched Piping
}

\author{
William Pao ${ }^{\text {a }}$, Fakhruldin M Hashim and Low Huei Ming \\ Mechanical Engineering Department, Universiti Teknologi PETRONAS, 31750 Tronoh, Perak, \\ MALAYSIA
}

\begin{abstract}
Understanding the behavior of two-phase flow through a T-junction is very important as it could potential contribute to massive cost saving in partial phase separation. The objectives of this paper focuses on the effect the inlet flow conditions on two-phase split efficiency under constant pressure gradient, and the effect of averaged bubble diameter on the mass flow split at the side arm outlet Via computational fluid dynamics tool, preliminary investigation found that beyond side to main arm diameter ratio of 0.75 , there is a drop of separation efficiency. The change of fraction of gas taken off is almost linearly and negatively proportional to the unit increment of initial gas saturation. When the side to main arm diameter ratios equal to 0.5 and 0.75 , the fraction of gas taken off is almost similar as far as the initial gas saturation is concerned.
\end{abstract}

\section{Introduction}

A T-junction consists of three main components which are the main, run and side arms, as shown schematically in Figure 1(a). When a two-phase mixture flows through a T-junction, the phases tend to separate in different proportions among the outlet arms. This phenomenon of phase maldistribution through a T-junctions has enourmous potential as simple, cost saving, passive partial separator to be used in pipeline networks in the petroleum industry. However, the efficiency of partial separation is not well understood.

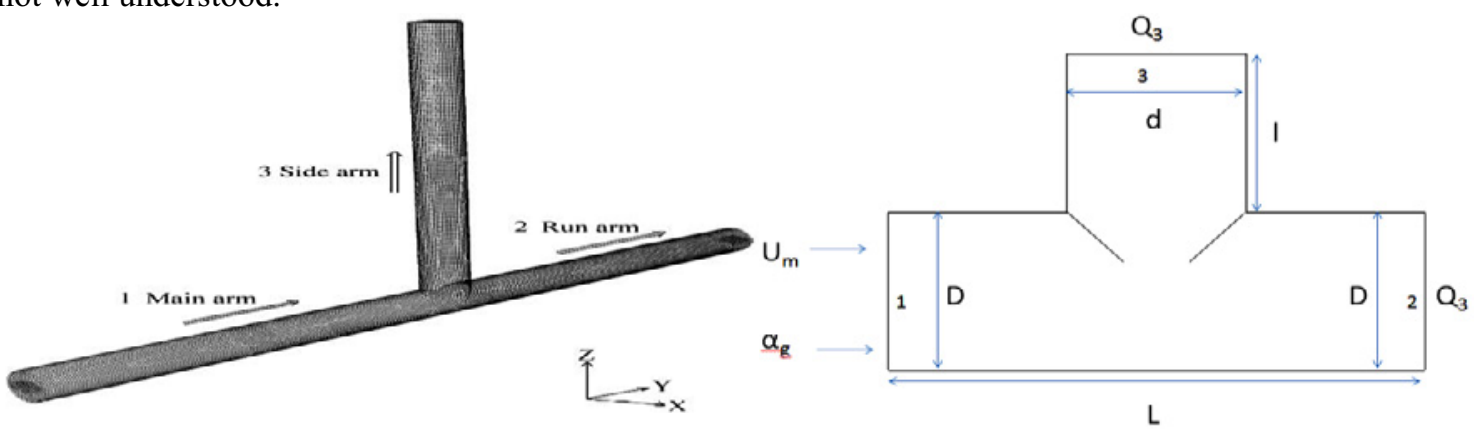

(a)

(b)

Figure 1. (a) Schematic of a T-junction [3]; (b) schematic T-junction with applied inlet and outlets boundary conditions

\footnotetext{
${ }^{a}$ Corresponding author: William.Paokings@petronas.com.my
}

This is an Open Access article distributed under the terms of the Creative Commons Attribution License 2.0, which permits unrestricted use, distribution, and reproduction in any medium, provided the original work is properly cited. 


\section{Literature Review}

According to Suzanne and Choi [1], less liquid was observed to split to the side-branch resulting in higher quality as the inlet liquid volume fraction increased in a uniform diameter $\mathrm{T}$-junction. However, according to Azzopardi et al. [2], the degree of phase separation seems to depend on the transit time between liquid-gas mixtures and the junction. The slower flows have more time to separate than the faster flow. Liu, et al. [3] concluded that gas phase tend to flow into the side arm for bubbly flow because of the pressure difference of the side arm to main arm is much larger than that for the run arm. Thus, the lower density gas will respond more easily to pressure gradient than liquid phase for the same pressure force. In addition, Margaris [4] reported that the separation efficiency at uniform $\mathrm{T}$-junction depends mainly on phase momentum, the existing flow pattern before the junction and also the gravity forces distribution on T-junction. Baker [5] stated that a reduction in the side-arm diameter will have two different effects which are the associated pressure drop and the axial distance available for take-off. The outlet with greater suction has a stronger influence on the flowing fluids and hence more significant the diversion in that direction.

According to Wren et al. [6,7], the main difference between a reduced and a regular T-junction is the pressure redistribution around the junction. For the same inlet conditions, the reduced side-branch causes a higher pressure drop compared with the uniform $\mathrm{T}$-junction. This is mainly due to the higher gas phase velocities encountered in the reduced side-arm for the same fraction of inlet gas flowing down the side arm. Griston and Choi [8] reported that the percentage of liquid split to the side-arm decreased further as the inlet vapor velocity decreased. The field tests showed that reduced side-arm diameter further decreased the percentage of liquid split to the side-branch. The liquid have lesser tendencies to flow through the restricted cross-sectional area of the side-arm. Furthermore, Azzopardi [9] also concluded that the effect of diameter ratio is strongest at lower gas rates and least at high gas and lower liquid flow rate conditions.

Pao et al. [10] showed only the aspects of diameter ratios on the fraction of gas take off. The objectives of this paper focuses on the effect the inlet flow conditions on two-phase split efficiency under constant pressure gradient, and the effect of averaged bubble diameter on the mass flow split at the side arm outlet.

\section{Governing Equations and Modeling Methodology}

The governing equations for two-phase flow model, as presented by Liu et al. [3] can be summarized as follows.

Two-phase continuity equation:

$$
\frac{\partial}{\partial t}\left(\alpha_{i} \rho_{i}\right)+\nabla \cdot\left(\alpha_{i} \rho_{i} \mathbf{v}_{i}\right)=0 \quad i=l \text { or } g
$$

Two-phase momentum balance:

$$
\frac{\partial}{\partial t}\left(\alpha_{i} \rho_{i} \mathbf{v}_{i}\right)+\nabla \cdot\left(\alpha_{i} \rho_{i} \mathbf{v}_{i} \cdot \mathbf{v}_{i}\right)=-\alpha_{i} \nabla p+\nabla \boldsymbol{\tau}_{i}+\alpha_{i} \rho_{i} \mathbf{g} \pm \mathbf{R}_{i, j} ; i, j=\left\{\begin{array}{l}
l, g \\
i \neq j
\end{array}\right.
$$

where $\mathbf{V}$ is the phase velocity, $\alpha$ is the volume fraction, $\rho$ density, $p$ is the hydrostatic pressure, $\mathbf{g}$ is the gravity vector, $\mathbf{R}$ is the interfacial interaction force between two phases and $\boldsymbol{\tau}$ is the stress tensor of the constituents. The subscript $i$ and $j$ refer to either liquid $(l)$ or gas $(g)$. The interfacial interaction force depends on pressure, cohesion and other effects and is subject to the conditions such that

$$
R_{l, g}=-R_{g, l}, R_{l, l}=0, R_{g, g}=0 .
$$


The stress tensor is given as follows:

$$
\boldsymbol{\tau}_{i}=\alpha_{i} \mu_{i}\left(\nabla \mathbf{v}_{i}+\nabla^{T} \mathbf{v}_{i}\right)+\alpha_{i}\left(\lambda_{i}-\frac{2}{3} \mu_{i}\right)\left(\nabla \cdot \mathbf{v}_{i}\right) \mathbf{I}
$$

where $\mu_{i}$ and $\lambda_{i}$ are the viscosity coefficients of the constituents. These equations are available in ANSYS Fluent 14.5, under the Eulerian Multiphase Model and hence will not be further elaborated. The development of numerical model of $\mathrm{T}$-junction for two-phase separation is based on the schematic T-junction in Figure1(b), where it consists of the main arm (1), run arm (2) and side arm (3), with symbols indicating the applied inlet/outlet conditions and geometric parameters considered in the present study. Other parameters such as the velocity inlet for water and gas, inlet gas saturation, flow rate weighting factor for both outlets and others are taken into consideration as shown in Table 1.

Table 1. Input paramètres for validation and parametric studies

\begin{tabular}{|l|c|}
\hline \multicolumn{1}{|c|}{ Input Parameters } & Parametric Study \\
\hline Main and run arm diameter, $\mathrm{D}[\mathrm{mm}]$ & 200 \\
\hline Side arm diameter, $\mathrm{d}_{3}[\mathrm{~mm}]$ & $100,150,200$ \\
\hline Total length of horizontal arm, $\mathrm{L}[\mathrm{mm}]$ & 4200 \\
\hline Total length of vertical arm, $\mathrm{l}_{3}[\mathrm{~mm}]$ & 2000 \\
\hline Density of liquid phase, $\rho_{1}\left[\mathrm{~kg} / \mathrm{m}^{3}\right]$ & 998.2 \\
\hline Density of gas phase, $\rho_{\mathrm{\Xi}}\left[\mathrm{kg} / \mathrm{m}^{3}\right]$ & $0.6-0.75$ \\
\hline Initial gas saturation, $\alpha_{\mathrm{gi}}$ & $0.7-0.96$ \\
\hline Inlet mixture velocity, $\mathrm{U}_{\mathrm{m}}(\mathrm{m} / \mathrm{s})$ & $8-15$ \\
\hline Inclination angle of gravity $(\mathrm{clockwise})$ & $0^{\circ}-45^{\circ}$ \\
\hline Overall mass split ratio, $\mathrm{Q}[-]$ & $0.3-0.97$ \\
\hline Operating pressure, $\mathrm{P}[\mathrm{kPa}]$ & 101 \\
\hline
\end{tabular}

Mesh independent study and model validation were described in the previous paper [10] and hence will not be repeated here. It is thus summarized here that the mesh used were having a density in between $4.6-4.8$ tetrahedrons $/ \mathrm{mm}^{3}$ and the FLUENT models were validated using experimental data from Davis et al. [11].

\section{Results and Discussions}

In order to simplify the discussion, the fraction is gas taken off is designated $f$. The effect of initial gas saturation with $U_{m}=15 \mathrm{~m} / \mathrm{s}$ and gas density of $0.6679 \mathrm{~kg} / \mathrm{m}^{3}$ is shown in Figure 2 . The higher the mass split ratio, the change of $f$ per unit increment of initial gas saturation increases, indicating the decline of separation efficiency. Interestingly, $f$ almost coincides with each other for diameter ratio of 0.75 and 1.0 for different mass split ratio. In other words, the perturbation of diameter ratio to fraction of gas taken off is minimal as far as the same mass split ratio is concerned. While $f$ exhibits a linear variation for diameter ratio of unity, the same cannot be said for diameter ratio 0.75 and 1.0. If we denote the initial gas saturation as $S_{g i}$, the non-linearity of $\partial f / \partial S_{g i}$ is most obvious when the prescribed mass split ratio close to unity. An interesting observation is that for diameter ratio 0.5 , mass split ratio does not seem to affect the gradient of the curve at all and $\partial f / \partial S_{g i}$ remains more of less constant.

Figure 3 shows the effect of gas density on fraction of gas taken off with different mass split ratio and an inlet mixture velocity of $12 \mathrm{~m} / \mathrm{s}$. Unsurprisingly, the change of fraction of gas taken off per unit of gas density variation decreases. In other words, the smaller the density difference between the twophase, the less effective it is to divert the gas phase into the side arm. 


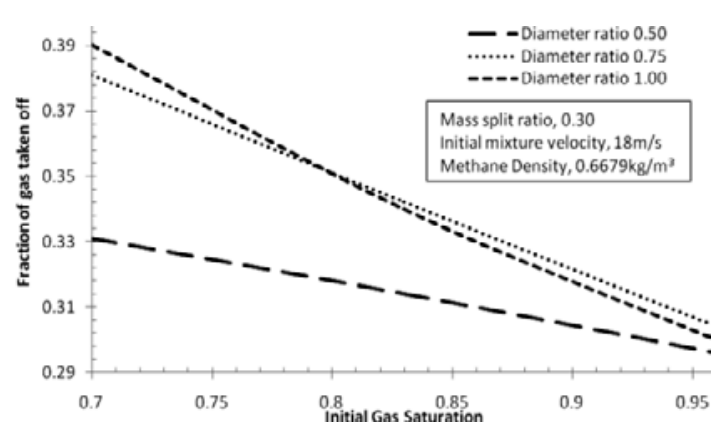

(a)

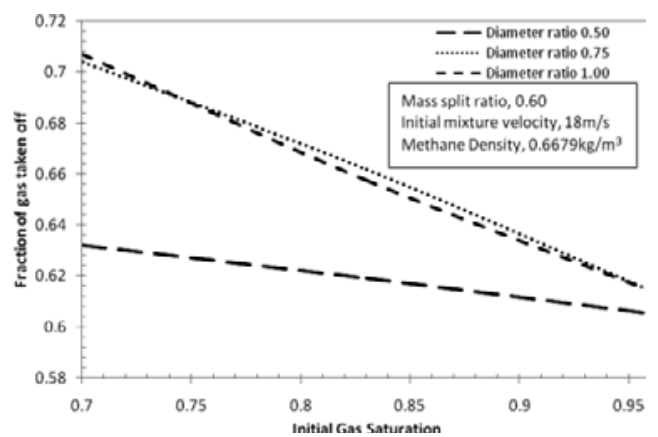

(b)

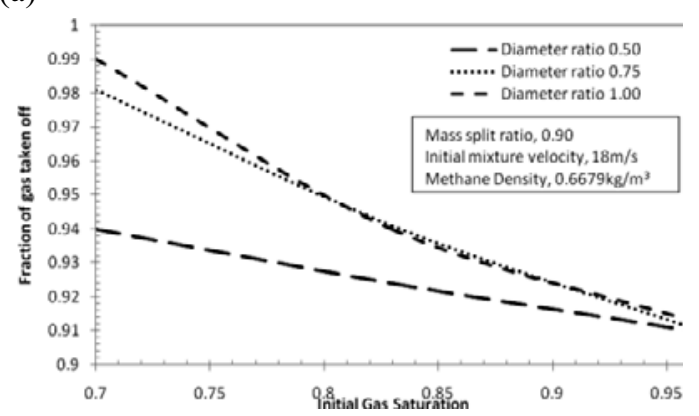

(c)

Figure 2. Effect of Initial gas saturation on Fraction of gas taken off with initial mixture velocity of $15 \mathrm{~m} / \mathrm{s}$ and Methane density of $0.6679 \mathrm{~kg} / \mathrm{m}^{3}$ (methane)

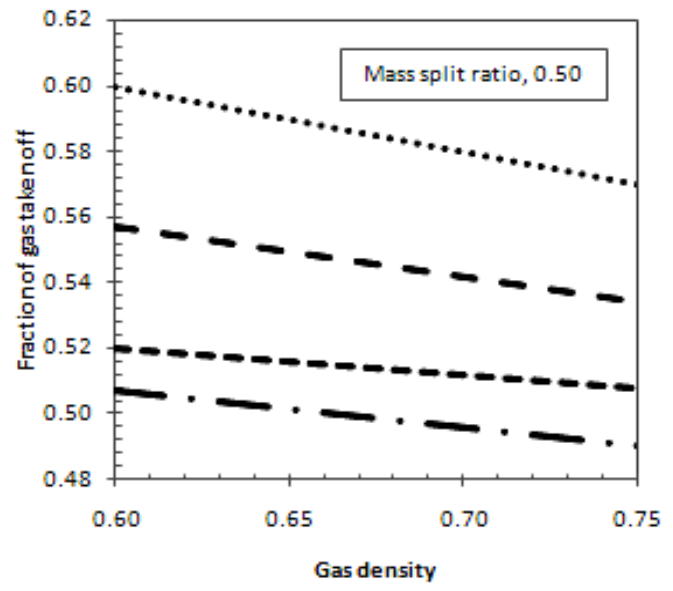

(a)

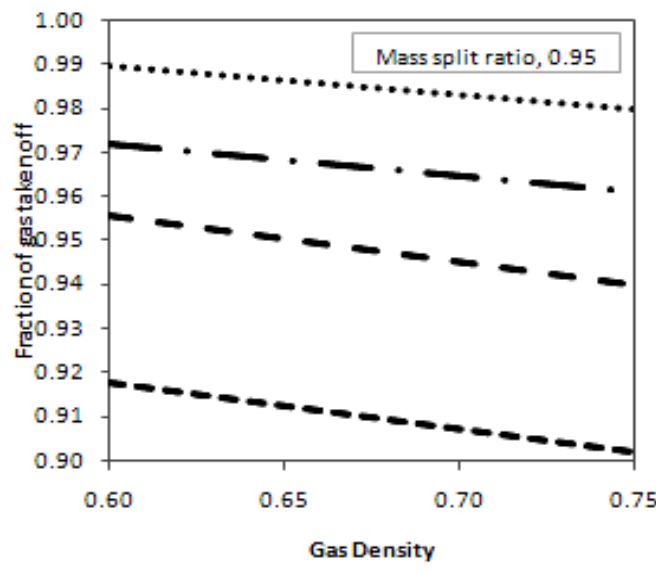

Initial Gas Saturation 0.7 at diameter ratio of 0.5 Initial Gas Saturation 0.7 at diameter ratio of 1.0

- - - - Initial Gas Saturation 0.96 at diameter ratio of 1.0 - - - - Initial Gas Saturation 0.96 at diameter ratio of 0.5

(b)

Figure 3. Effect of gas density on fraction of gas taken off with overall mass split ratio of 0.50 and 0.95 with an inlet mixture velocity of $12 \mathrm{~m} / \mathrm{s}$ 


\section{Conclusion}

This present paper focused on two-phase wet-gas separation in T-junction with horizontal main arm and vertical side arm using methane gas and water as working fluids. Through numerical simulation, the significance of diameter ratio, initial gas saturation, overall mass split ratio, averaged inlet mixture velocity and gas density are studied. It is found that the most influential factor is the overall mass split ratio followed by the initial gas saturation and diameter ratio of the $\mathrm{T}$-junction. The effects due to inlet velocity of the mixture and gravity inclination are almost negligible relative to other factors. The diameter ratio of $0.5-0.75$ is determined to be the optimum range for an efficiency separation and beyond 0.75 , the efficiency starts to flatten. The higher the gas saturation, the less efficient it is for the split to happen.

\section{References}

[1] G. Suzanne, J. Choi. Two-Phase Flow Splitting at Side-Branching Tees. In SPE Western Regional Meeting, May, 1998.

[2] B.J. Azzopardi, S. Rea. Phase separation using a simple T-junction. In SPE Annual Technical Conference and Exhibition, Oct, 2000.

[3] Y. Liu, W. Li. Numerical Simulation On Two Phase Bubbly Flow Split In A Branching Tjunction. International Journal of Air-Conditioning and Refrigeration. 19(4):253-262, 2011

[4] D. P. Margaris. T-junction separation modelling in gas-liquid two-phase flow. Chemical Engineering and Processing: Process Intensification. 46(2):150-158, 2007.

[5] G. Baker. Separation and control of gas-liquid flows at horizontal T-junctions. $\mathrm{PhD}$ dissertation, University of Nottingham, 2003.

[6] E.M.K. Wren. 2001. Geometric effects on phase split at a large diameter T-junction. Doctoral dissertation, University of Nottingham, 2001.

[7] E. Wren, G. Baker, B.J. Azzopardi, R. Jones. Slug flow in small diameter pipes and Tjunctions. Experimental Thermal and Fluid Science, 29(8):893-899. 2005.

[8] S. Griston, J. H. Choi. 1998. Two-phase flow splitting at side-branching tees. SPE 46237 presented at the SPE Western Regional Meeting, Bakersfield, CA, May, 1998.

[9] B. J. Azzopardi. 1999. The effect of side arm diameter on phase split at T-junctions. SPE Annual Technical Conference and Exhibition, Oct, 1999.

[10] H.M Low, W Pao, F.M. Hashim. Numerical investigation of two phase separation in T-junction. International Conf. Mathematics, Engineering \& Industrial Application (ICoMEIA 2014), P. Pinang, 3-5 May 2014.

[11] M.R. Davis, B. Fungtamasan. Two-phase flow through pipe branch junctions. International Journal of Multiphase Flow. 16(5):799-817, 1990. 